\title{
Construct Validity of Careful vs. Expeditious Reading Skills
}

\author{
Gholamreza Hessamy \\ Department of Applied Linguistics, Payame Noor University \\ PO Box 19395-4697, Iran \\ E-mail: yhessamy@yahoo.com
}

Soheila Dehghan Suldaragh (Corresponding author)

MA in TEFL from Payame Noor University, Iran

E-mail: soheiladehghan60@yahoo.com

Received: February 27, 2013 Accepted: July 16, 2013 Published: July 17, 2013

doi:10.5296/ijele.v1i3.4018 URL: http://dx.doi.org/10.5296/ijele.v1i3.4018

\begin{abstract}
An important aspect of reading research concerns the nature of the divisibility of the construct. The present study examined the construct validity of expeditious and careful reading. To this end, first, empirical data was gathered to see whether there was any significant difference in the performance of EFL learners at the macro-levels of expeditious vs. careful reading. Then, the possible relationships among the underlying sub-skills hypothesized to be utilized in careful reading, i.e., 'understanding explicit information' and 'making inferences', and expeditious reading, i.e., 'skimming' and 'scanning', were studied. To fulfill the purpose of the study, a reading comprehension test measuring these sub-skills was prepared and administered to 200 Iranian English majors. Data was analyzed using paired-sample t-test and factor analysis. The results showed that in spite of a significant difference in the performance of subjects on expeditious vs. careful reading items, all the sub-skills operationalized in the instrument were measuring aspects of one underlying construct of L2 reading comprehension ability. Implications for testing and teaching L2 reading are discussed.
\end{abstract}

Keywords: careful reading, expeditious reading, construct validity, reading sub-skills 


\section{Introduction}

Many studies have investigated the nature of L2 reading ability by focusing on the psychological reality of reading skills (e.g. Lumley, 1993; Rosenshine, 1980; Rost, 1993; Weir, Huizhong, \& Yan, 2002). Alderson (2000) holds that there is little agreement over whether identifying and labeling separate skills of reading is possible, and its theoretical nature is still highly controversial. Generally, in his opinion, studies which have addressed the nature of reading skills support one of these three positions: (a) reading is a unitary skill, (b) reading is multi-divisible, and (c) reading is bi-divisible.

Lunzer and Gardner (1979), Lunzer, Waite and Dolan (1979), Rosenshine (1980), and Rost (1993), among others, studied the nature of reading empirically and identified only a single factor of reading ability. The unitary view assumes that reading is a single, holistic, undifferentiated ability and the measurement of this general ability can be a good indication of the overall reading ability of students (Weir et al., 2002). Qualitative studies supporting the unitary view include Alderson (1990) and Alderson and Lukmani (1989) which found no agreement among the judges in identifying the skill tested by each item, or on the level of the skill: whether it is 'higher order' or 'lower order'. However, Weir, Hughes, \& Porter (1990) and Matthews (1990) criticized aspects of Alderson's (1990) methodology. They refer to the experience of judges and inadequate explanation given on the terms 'higher' and 'lower' order.

In supporting the bi-divisible view of reading, Alderson (2000) points to the previous research on reading showing more evidence and support for the assumption that reading can be divided into two main components: 'decoding (word recognition)' and 'comprehension'. Weir et al. (2002) refer to Guthrie and Kirschs (1987), Berkoff (1979), Carver (1992), and Farr (1968) all identifying two factors in their analyses.

On the other hand, Drum, Calfee, \& Cook (1981), Pollitt, Hutchinson, Entwistle, \& DeLuca (1985), Davey (1988), and Carroll (1993) are examples of quantitative studies supporting a multi-divisible view of reading (Alderson, 2000). Qualitative studies in support of multi-divisibility include Weir et al. (1990), Anderson, Bachman, Perkins, \& Cohen (1991), Lumley (1993), and Weakley (1993). Researchers such as Cummings (1983), Rost (1993), and Alderson (2000) claimed that it might be appropriate to apply the multi-divisible view of reading to the early stages of learning to read in which reading consists of interrelated sub-skills, while as reading ability develops, its sub-skills become so integrated that can be hardly identified during the reading process. Thus, according to them, at advanced levels it is better to hold a unitary view in teaching and testing. Nonetheless, the usefulness of a unitary view to both teaching and testing practice at higher levels of proficiency is certainly an important issue to consider.

\subsection{Testing Careful Vs. Expeditious Reading Ability}

Hughes (2003) believes that testing of reading ability is more complicated than what people think it is. He maintains that even language testers don't agree on the nature of the reading sub-skills may wish to measure. In addition, even in the case of agreement in the existence of a particular skill, one cannot confidently assert that an item has successfully measured it. He 
argues that although the sub-skills of reading may not have been definitely demonstrated to exist, we believe they exist, because we, as readers, are aware of at least some of them, and therefore, should not exclude them from our tests. He divides reading into expeditious reading (skimming, search reading, and scanning) and careful reading. The procedural difference is basically in the time allocated to respond to the items.

Urquhart and Weir (1998) hold that separate tests are needed to measure careful and expeditious reading. The time to answer expeditious reading items should be strictly controlled to ensure that the passages have been processed in the expected manner. Conversely, careful reading tests which represent real life reading require more time to reach the desired level of comprehension.

On the importance of expeditious reading strategies, Urquhart and Weir (1998) maintain that in addition to careful reading skills, students need to be able to read expeditiously to quickly extract main ideas or decide whether a part of a text is relevant to their purposes. They believe that in spite of its importance, expeditious reading has been overlooked by testers, researchers, and developers of reading models. Despite the little attention paid to expeditious reading, there are some research studies (e.g. Guthrie \& Kirsch, 1987; Weir et al., 2002; Weir \& Khalifa, 2008; and $\mathrm{Wu} \& \mathrm{Lin}, 2008)$ which have investigated the nature of expeditious reading and its relationship with careful reading. They mainly found that subjects performed differently on tasks involving careful reading vs. those requiring readers to locate information by selective sampling of texts.

\subsection{Defining the Constructs}

In reading research and discussions, careful reading is usually preferred to other types (e.g. skimming or search reading) by most of the educationalists and psychologists because of its main role in learning. It involves reading to extract full meaning from the material (Weir \& Khalifa, 2008) and it is closely related to 'reading to learn' (Weir et al., 2002). Hence, in reading the textbooks, we use more of it (Urquhart \& Weir, 1998). Hughes (2003) provides a list of twenty operations for careful reading. Other writers have also provided lists of sub-skills involved in careful reading (e.g. Davis, 1968; Munby 1978; Lunzer \& Gardner, 1979; Grabe, 1991; Weir, 1993; Urquhart \& Weir, 1998; Weir et al. 2002). The present study focused on two key operations present in almost any categorization of reading skills, namely, 'understanding explicitly stated information' and 'making inferences'. It was believed that with so much controversy regarding the nature of underlying reading sub-skills, these two operations can best represent what is generally referred to as careful reading.

In Urquhart and Weir's (1998) opinion, to identify explicitly stated information, the reader should decode the whole text. In other words, the text should be read from beginning to the end in a linear and sequential fashion, returning to the previous parts only as required. On the other hand, making inferences is a 'creative process' by which the reader relates the knowledge of himself to what is stated in a text in order to make it coherent (Weir \& Khalifa, 2008). Hughes (2003, p.139) enumerates four types of inferences as 'inferring the meaning of an unknown word from context', 'making propositional informational inferences', 'making propositional explanatory inferences', and 'making pragmatic inferences'. Generally, making 
propositional inferences is based upon the information provided in the text, and making pragmatic inferences requires a combination of information from the text and knowledge from outside the text (ibid).

According to Weir and Khalifa (2008), unlike careful reading whereby the reader intends to draw full meaning from the material, expeditious reading involves "quick, selective and efficient reading to access desired information in a text" (p.5). The speed with which a reader processes a text is a crucial factor distinguishing careful from expeditious reading. Expeditious reading can act as a good indicator of the difference between L1 and L2 readers (Urquhart \& Weir, 1998). It is mostly considered as involving two operations: skimming and scanning.

Grellet (1987) describes skimming as a quick reading of a text to get the central meaning of it, to understand how it is organized, or to obtain an idea of the tone or the intention of a writer. Urquhart and Weir (1998) enumerate operations which might be involved in skimming as: identifying the source, reading titles and subtitles, reading carefully the abstract, introductory and concluding paragraphs, first and last sentence of each paragraph, identifying discourse markers, skipping clusters of details, noting repeated key words, and glancing at any non-verbal information.

According to Urquhart and Weir (1998), scanning involves reading quickly a text to find out a specific symbol or group of symbols like a particular word, phrase, name, figure, or date. In this process, most of the text is ignored and its linearity is not observed. In Grellet's (1987) opinion, scanning is done at a higher speed than skimming and after finding the target, the reading stops.

In this study the construct validity of expeditious and careful reading through the following research questions was investigated:

1) Is there any significant difference in the performance of EFL learners on expeditious vs. careful reading test items?

2) What is the relationship between the underlying skills involved in careful and expeditious reading?

\section{Method}

\subsection{Participants}

200 junior and senior English majors participated in the study. Their level of language proficiency was considered to range from intermediate to upper-intermediate based on the academic courses they had passed on language skills. They were studying TEFL, English Translation, and English Literature.

\subsection{Instrumentation}

In order to carry out this study, a reading comprehension test was used (see Appendix). This test consisted of four sections and measured two operations of expeditious and careful reading. Each section had seven questions in the multiple-choice (MC) format. The 
participants had 10 minutes to complete the first two sections of the test which required expeditious reading skills of skimming and scanning, and 20 minutes for sections three and four which required careful reading. Therefore, the whole test lasted for 30 minutes for answering $28 \mathrm{MC}$ questions.

The first section of the test contained a passage with 376 words and seven questions designed for skimming. This was followed by a passage with 520 words and seven questions for scanning. Participants had five minutes to answer the questions of each section. Sections three and four measured 'understanding explicitly stated information' and 'making inferences'. Each section with about 300 words had an equal number of seven questions to be answered in 10 minutes. Table 1 shows the specifications for the instrument of the study.

Table 1. Table of specifications for the test of reading skills

\begin{tabular}{|c|c|c|c|c|}
\hline \multicolumn{2}{|c|}{ Types of skills/sub-skills } & \multirow{2}{*}{$\begin{array}{l}\text { section } \\
1\end{array}$} & \multirow{2}{*}{$\begin{array}{l}\text { Items } \\
1-7\end{array}$} & \multirow{2}{*}{$\begin{array}{l}\text { Time } \\
\text { limit } \\
5 \mathrm{~min} .\end{array}$} \\
\hline Expeditious & Skimming & & & \\
\hline & Scanning & 2 & $8-14$ & $5 \mathrm{~min}$. \\
\hline \multirow[t]{2}{*}{$\begin{array}{l}\text { Careful } \\
\text { reading }\end{array}$} & $\begin{array}{l}\text { Understanding } \\
\text { Explicitly stated } \\
\text { information }\end{array}$ & $3-4$ & 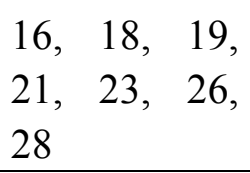 & $10 \mathrm{~min}$. \\
\hline & Making inferences & $3-4$ & 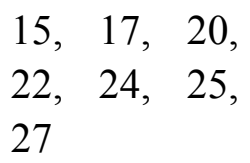 & $10 \mathrm{~min}$. \\
\hline
\end{tabular}

To test careful reading, two passages of Various TOEFL PBT Reading Questions (2003) were used. Among the questions of these passages, items which measured 'understanding explicitly stated information' and 'making inferences', based on the definitions given by Hughes (2003), were chosen by the researchers and two other experts to be included in the test.

Since a standard test of expeditious reading was not available, a number of skimming and scanning tests were retrieved from the Internet and their readability indices were calculated through SMOG formula. After changing some parts of the texts and questions, finally, two texts for skimming (BBC Skillswise, 2009, May 17) and scanning (Speed Reading Test Online, n.d.) with the readabilities of 13.05 and 15.25 were selected as their indices were close to those of the TOEFL (13.77 and 15.39).

The allocated time for each section was determined after piloting the test with five EFL 
learners at the appropriate level of proficiency. Then, the test was piloted with 25 subjects similar to the target population to determine the reliability of the whole test and to run item analysis for the test of expeditious reading. The reliability of the whole test calculated through KR-21 formula turned out to be 0.69 . Although this was not very high, considering the number of items and subjects in the pilot stage, it was acceptable for the purpose of the study. Furthermore, the results of the item analysis revealed that the expeditious reading items functioned well with this group of students.

\subsection{Procedure}

Before administration of the test, the consent was obtained from the authorities and teachers who had agreed to assist us in conducting the study. The test was administered in the regular class hours of the universities which cooperated in the study. Before the administration, the participants were informed about the number of the sections and their time limits for each. Since for the goals of the study strict timing for each section of the test was of utmost importance, each section was collected after its allocated time was finished and then the next section was distributed. The test-takers were required to mark the answers on an answer sheet. In order to motivate the participants to cooperate in the study, the highest scores in the classes were rewarded.

Counterbalancing of the sections was used in the papers to reduce the possibility of the participants' ignorance of a particular passage due to its positioning at the end of the test. It also largely decreased the chances for cheating. Students were presented with sections one and two measuring expeditious reading skill for the first 10 minutes and sections three and four measuring careful reading skill for the next 20 minutes of the allowed time of the test. In each class, the students were divided into group A and B. At the first five minutes of the test, group A was presented with section one and group B with section two. During the next five minutes, group A received section two and group B had section one. After taking the first part of the test, students were prepared for the second part. Like the first part, group A was presented with section three and group B with section four. After 10 minutes, group A received section four and group B section three. On the whole, the test was administered in nine classes and all of the students answered the four sections. As mentioned before, the time devoted to each task was strictly controlled. During administration, two reminders were given to the subjects three and two minutes before the end of the time limit for expeditious reading sections, and five and three minutes left for careful reading sections.

\section{Results and Discussion}

The internal consistency of the 28 reading items was calculated. Using Cronbach alpha, it was 0.73 . Table 2 shows the descriptive statistics for the reading test. 
Table 2. Descriptive statistics

\begin{tabular}{|l|l|l|l|l|l|}
\hline Reading & Mean & N & $\begin{array}{l}\text { Std. } \\
\text { Deviation }\end{array}$ & Total Mean & Total SD \\
\hline EXPEDITIOUS & 6.01 & 200 & 2.566 & & \\
\hline CAREFUL & 6.86 & 200 & 2.767 & 12.87 & 4.794 \\
\hline
\end{tabular}

The first research question of the study concerned the difference between L2 expeditious and careful reading skills. This question was reformulated as a null hypothesis of "there is no significant difference in the performance of EFL learners on expeditious vs. careful reading test items". The results of data analysis using paired-sample t-test showed a significant difference in the performance of the subjects on expeditious vs. careful reading items (Table $3)$.

Table 3. Paired-sample t-test (expeditious vs. careful reading)

\begin{tabular}{|c|c|c|c|c|c|c|}
\hline & \multicolumn{3}{|c|}{ Paired Differences } & \multirow[b]{2}{*}{ f } & \multirow[t]{2}{*}{ Df } & \multirow[t]{2}{*}{ Sig. (2-tailed) } \\
\hline & Mean & $\begin{array}{l}\text { Std. } \\
\text { Deviation }\end{array}$ & $\begin{array}{l}\text { Std. } \\
\text { Error of } \\
\text { Mean }\end{array}$ & & & \\
\hline $\begin{array}{l}\text { EXPED } \\
\text { CARE }\end{array}$ & -.850 & 2.320 & .164 & 5.180 & 199 & .000 \\
\hline
\end{tabular}

The second question of the study was also investigated through the null hypothesis of "there is no relationship between the sub-skills involved in careful and expeditious reading skills". Factor analysis through Varimax rotation was run to examine the underlying construct of the variables involved in careful reading, i.e., 'understanding explicitly stated information' and 'making inferences', and expeditious reading, i.e., 'skimming' and 'scanning'. Table 4 shows the amount of variance explained by each factor. 


\section{Ml Macrothink}

Table 4. Total variance explained

\begin{tabular}{|c|l|l|l|l|l|l|}
\hline \multicolumn{2}{|l|}{ Total Variance Explained } \\
\hline \multirow{2}{*}{} & \multicolumn{3}{|l|}{ Initial Eigenvalues } & \multicolumn{2}{l|}{$\begin{array}{l}\text { Extraction Sums of Squared } \\
\text { loadings }\end{array}$} \\
\cline { 2 - 7 } Variables & Total & $\%$ of variance & $\begin{array}{l}\text { Cumulative } \\
\%\end{array}$ & Total & $\%$ of Variance & $\begin{array}{l}\text { Cumulative } \\
\%\end{array}$ \\
\hline $\mathbf{1}$ & 2.274 & 56.859 & 56.859 & 2.274 & 56.859 & 56.859 \\
\hline $\mathbf{2}$ & .693 & 17.323 & 74.181 & & & \\
\hline $\mathbf{3}$ & .527 & 13.171 & 87.353 & & & \\
\hline $\mathbf{4}$ & .506 & 12.647 & 100.000 & & & \\
\hline
\end{tabular}

Eigenvalues measure the amount of variation in the total sample accounted for by each factor. According to Kaiser Criterion, all of the components with eigenvalues under 1.0 should be dropped from the analysis since they are contributing little to the explanation of variance in the variables. According to the table, only the first factor has an eigenvalue of 2.274 which is more than one. Therefore, only one factor was extracted which accounted for $56.85 \%$ of the variance. Table 5 shows the factor loadings for the sub-skills.

Table 5. Factor extraction

\begin{tabular}{|l|l|}
\hline Sub-skill & Factor 1 \\
\hline Scanning & .778 \\
\hline Making inferences & .772 \\
\hline Skimming & .749 \\
\hline Understanding explicit information & .716 \\
\hline
\end{tabular}


As the Table shows, all the sub-skills loaded on a single factor with good correlations. In other words, the four components of the test all tapped the same underlying construct of L2 reading comprehension ability. Therefore, these sub-skills are aspects of an overall ability as they have enough in common and the second hypothesis is clearly rejected.

The findings of the present study can be regarded as further empirical evidence for the unitary view of reading. It can be concluded that although differential performance of learners on different types of reading (careful vs. expeditious) can indicate that there are still differences in the processes involved in what we collectively call reading, the overall ability of $\mathrm{L} 2$ reading is unitary in terms of the underlying construct.

With regard to the second research question, the findings are in line with Rost (1993), Lunzer et al. (1979), Spearitt (1972), and Carver (1992). It should be mentioned here that the unitary nature of reading is also discussed in relation to the proficiency level of the learners (Rost, 1993; Urquhart \& Weir, 1998). Alderson (2000) argues that as the proficiency of second language learners increases, the entire reading process are so connected to each other that although different kinds of skills may be required to accomplish a reading task, they cannot be clearly distinguished from one another. Therefore, it can be argued that since the participants of this study were intermediate to upper-intermediate, their reading skills could be somehow intermingled as an overall ability. Thus, in relation to the second hypothesis, one may conclude that using the skills approach to teaching and testing reading ability of the learners may be more appropriate for low-level foreign language learners, but not for higher levels.

On the other hand, the rejection of the first null hypothesis may suggest that expeditious and careful reading result in differential performance of the test-takers. In this regard, the findings are specifically in line with Weir et al. (2002), Wu \& Lin (2008) and Guthrie \& Kirsch (1987). Weir et al. (2002) who investigated learners' ability in careful and expeditious reading at local and global levels found that subjects performed differently in each part of the test, namely, expeditious and careful reading. Wu and Lin (2008) tried to investigate the strengths and weaknesses of advanced EFL learners in taking a reading comprehension test. They also found that the students performed differently in careful and expeditious reading. Similarly, Guthrie \& Kirsch (1987, cited in Weir \& Khalifa, 2008) examined a group of engineers' reading performance in different sub-skills of reading. They found that their subjects performed differently in tasks involving reading carefully and those requiring expeditious reading strategies.

The results probably highlight the peculiarities of careful and expeditious reading operations manifested in the relative strengths and weaknesses of the learners on the two macro-skills. It can further emphasize that such operations are not practically the same and each demands special training and practice. Of course, the fact that EFL learners usually do not get the same amount of instruction and practice on careful and expeditious reading skills can somehow explain their differential performance. Consequently, the overall results seem to support a skills-based approach to teaching and testing L2 reading comprehension. 


\section{Conclusion}

In spite of the lack of consensus over the divisibility of reading skill in the literature, the results of the present study provided additional empirical evidence on the issue. Therefore, one can conclude that although expeditious and careful reading skills have the same basis, i.e., reading ability, which makes them different from other constructs, because of their peculiarities, they are also different which results in differential performance of the subjects in a test of the two macro-skills. Although at first glance the findings might seem paradoxical, they are very illuminating in the sense that they can also explain a history of contradictory findings on the divisibility argument we have had so far. The fact that different studies have come up with unitary or componential models of reading can be due to the fact that we can basically look at the construct of reading at two levels of analysis. At one level, we are dealing with a psychological construct which is considerably different from other constructs because it shows some internal unity, although it may not be so monolithic. On the other hand, when we look at the construct from the inside, it is made of components that show differences in operations involved, and as a result, theoretical and empirical evidence may suggest a componential conceptualization of the construct. The latter view is as acceptable as the former if the outside vs. the inside view of the construct is taken into consideration. Of course, in the teaching and testing practice, the componential models are undoubtedly of much more practical utility while the unitary view has little applicability.

The implication of the results for testing practice might be the suggestion that in a reading proficiency test, there should be sub-tests with different question types to measure the expeditious and careful reading skills alike. Similarly, teachers and material writers can be informed that teaching one of them cannot necessarily result in the development of the other. Consequently, expeditious and careful reading skills with the specific features relating to each should be taught and practiced separately.

\section{References}

Alderson, J. C. (1990). Testing reading comprehension skills (Part one). Reading in a Foreign Language, 6(2), 425-438.

Alderson, J. C. (2000). Assessing reading. Cambridge: Cambridge University Press.

Alderson, J. C., \& Lukmani, Y. (1989). Cognition and reading: Cognitive levels as embodied in test questions. Reading in a Foreign Language, 5(2), 253-270.

Anderson, N. J., Bachman, L., Perkins, K., \& Cohen, A. (1991). An exploratory study into the construct validity of a reading comprehension test: Triangulation of data sources. Language Testing, 8, 41-66. http://dx.doi.org/10.1177/026553229100800104

BBC Skillswise. (2009, May 17). Retrieved from http://www.bbc.co.uk/skillswise/words/grammar/

Berkoff, N. A. (1979). Reading skills in extended discourse in English as a foreign language. Journal of Research in Reading, 2, 95-107. http://dx.doi.org/10.1111/j.1467-9817.1979.tb00197.x 


\section{Macrothink}

International Journal of English Language Education

ISSN 2325-0887

2013, Vol. 1, No. 3

Carroll, J. B. (1993). Human cognitive abilities. Cambridge: Cambridge University Press.

Carver, R. P. (1992). What do standardized tests of reading comprehension measure in terms of efficiency, accuracy and rate? Reading Research Quarterly, 27, 347-359. http://dx.doi.org/10.2307/747674

Cummings, O. W. (1983). Differential measurement of reading comprehension skills for students with discrepant subskill profiles. St. Charles, IL: Arthur Anderson \& Co, Center for Professional Education.

Davey, B. (1988). Factors affecting the difficulty of reading comprehension items for successful and unsuccessful readers. Experimental Education, 56, 67-76.

Davis, F. B. (1968). Research in comprehension in reading. Reading Research Quarterly, 3, 499-545. http://dx.doi.org/10.2307/747153

Drum, P. A., Calfee, R. C., \& Cook, L. K. (1981). The effects of variables on performance in reading comprehension tests. Reading Research Quarterly, 16, 486-514. http://dx.doi.org/10.2307/747313

Farr, R. C. (1968). The convergent and discriminant validity of several upper level reading tests. Yearbook of the National Reading Conference, 17, 181-191.

Grabe, W. (1991). Current development in second language reading research. TESOL Quarterly, 25(3), 375-406. http://dx.doi.org/10.2307/3586977

Grellet, F. (1987). Developing reading skills. Cambridge: Cambridge University Press.

Guthrie, J. T., \& Kirsch, I. S. (1987). Distinctions between reading comprehension and

locating information in text. Journal of Educational Psychology, 79, 220-227. http://dx.doi.org/10.1037/0022-0663.79.3.220

Hughes, A. (2003). Testing for language teachers ( $2^{\text {nd }}$ ed.). Cambridge: Cambridge University Press.

Lumley, T. (1993). The notion of subskills in reading comprehension tests: An EAP example. Language Testing, 10(3), 211-234. http://dx.doi.org/10.1177/026553229301000302

Lunzer, E., \& Gardner, K. (Eds.) (1979). The effective use of reading. London: Heinemann Educational Books.

Lunzer, E., Waite, M., \& Dolan, T. (1979). Comprehension tests. In E, Lunzar, \& K. Gardner (Eds.), The effective use of reading (pp. 37-71). London: Heinemann Educational Books.

Matthews, M. (1990). Skill taxonomies and problems for the testing of reading. Reading in a Foreign Language, 7(1), 511-517. $\quad$ Retrieved from http://nflrc.hawaii.edu/rfl/pastissues/rfl71matthews.pdf

Munby, J. (1978). Communicative syllabus design. Cambridge: Cambridge University Press.

Pollitt, A., Hutchinson, C., Entwistle, N., \& DeLuca, C. (1985). What makes exam questions 


\section{Macrothink}

International Journal of English Language Education

ISSN 2325-0887

2013, Vol. 1, No. 3

difficult? An analysis of 'O' grade questions and answers. Edinburgh: Scottish Academic Press.

Rosenshine, B. V. (1980). Skill Hierarchies in Reading Comprehension. In R. J. Spiro, B. C. Bruce, \& W. F. Brewer (Eds.), Theoretical issues in reading comprehension (pp. 535-559). Hillsdale, NJ: Lawrence Erlbaum.

Rost, D. H. (1993). Assessing the different components of reading comprehension: Fact or fiction. Language Testing, 10, 79-92. http://dx.doi.org/10.1177/026553229301000105

Spearitt, D. (1972). Identification of sub skills of reading comprehension by maximum likelihood factor analysis [Abstract]. Reading Research Quarterly, 8(1), 92-111. Retrieved from http://www.jstor.org/stable/746983

Speed Reading Test Online. (n.d.). Retrieved from http://www.readingsoft.com/index.html

Urquhart, A., \& Weir, C. J. (1998). Reading in a second language: Process, product and practice. London: Longman.

Various TOEFL PBT Reading Questions. (2003). Retrieved from http://www.urch.com/famous/toefl-reading/20308-various-toefl-pbt-reading-questions.html

Weakley, S. (1993). Procedures in the content validation of an EAP proficiency test of reading comprehension. Unpublished MATEFL dissertation CALS, University of Reading.

Weir, C. J. (1993). Understanding and developing language tests. Hamel Hewpstead: Prentice Hall.

Weir, C. J., Hughes, A., \& Porter, D. (1990). Reading skills Hierarchies, implicational relationships and identifiability. Reading in a Foreign Language, 7(1), 505-510.

Weir, C. J., Huizhong, Y., \& Yan, J. (2002). An empirical investigation of the componentiality of $L 2$ reading in English for academic purposes. Cambridge: Cambridge University Press.

Weir, C. J., \& Khalifa, H. (2008). A cognitive processing approach towards defining reading comprehension. Cambridge English for Speakers of Other Languages, (31), 2-10. Retrieved from http://www.cambridgeesol.org/rs_notes/rs_nts31.pdf

Wu, J. R. W., \& Lin, A. C. W. (2008). Assessing English proficiency at advanced level: Testers feedback to teaching. $25^{\text {th }}$ International Conference of English Teaching and Learning. Retrieved from http://www.lttc.ntu.edu.tw/academics/geptresearch

\section{Appendix}

\section{Test of Reading Skills}

\section{Section 1}

You have 5 minutes to quickly read the text and answer the questions that follow it. All the 
answers must be marked on the ANSWER SHEET.

\section{An extract from 'The path that led nowhere'}

The mist clouded Georgina's view when she woke up early that morning. Looking out of her sash window, Georgina had expected to be greeted with the promised view of rolling hills and animals grazing in the meadow below. Unfortunately, the mist meant that she couldn't see for more than 20 meters.

Georgina had looked forward to her annual holiday. Working hard in the ministry of justice, the daily labor had started to get to her and Georgina had had little time for pleasures such as relaxation. The holiday had been booked for weeks. Georgina had looked forward to a country departure, far away from the hustle and bustle of drudgery. This apartment in an eighteenth-century mansion had caught her eye because it promised exquisite cuisine, beautiful interior decoration and a range of country pursuits such as clay pigeon shooting, horse riding, cultivating and flower arranging.

This Saturday morning though, many activities were cancelled as a result of the low-lying mist. Anxious not to permit the day slip away, Georgina decided that a walk through the adjacent forest would enable her to relax. Therefore, Georgina started precisely after eating the breakfast.

Georgina headed towards the forest with a small packed lunch in case the mist prevented her from returning to the mansion before lunchtime. While Georgina walked along the pathway, the twigs snapped under her feet and the dew from the trees dripped on to his shoulder. Georgina heard the birds sitting in the trees above her, permitting her understand that she wasn't alone.

Georgina had been described about a clearing in the middle of the forest that would surprise her with a comfortable bench, often used in the warmer summer months. Georgina thought she was heading in the right direction but, over sixty minutes later, she still hadn't reached the comfortable bench. Gradually, Georgina was getting worried. Another hour passed...then another hour... Georgina was still walking amongst the tall oak and pineapple trees. Georgina decided to rest and sat on a fallen tree to experience her lunch.

Feeling better after a relaxation and some food, Georgina continued to endeavor to find her way back to her comfortable holiday accommodation. Undoubtedly, Georgina would be back there immediately?

1. This piece of text can be described as:
a. Informative
b. Persuasive
c. Instructive
d. descriptive 
2. The weather in this story can best be described as:
a. Sunny
b. misty
c. humid
d. cold

3. Why Georgina was in the apartment?
a. It was her apartment.
b. It was her parents' apartment.
c. It was her best friend's apartment.
d. She was on holiday.

4. This extract doesn't mention:
a. the birds in the forest
b. how Georgina got to the hotel in the first place
c. why Georgina wanted to go to this hotel
d. the weather

5. What kind of story is this?
a. a romance
b. a horror story
c. a mystery
d. a comedy

6. How many people are featured in this story?
a. one
b. three
c. two
d. four people and a dog

7. Which of these has the right events in the right order?

a. Georgina eats her lunch, and then decides to go for a walk. However, she gets lost and has to stay overnight at a hotel.

b. Georgina goes on holiday, decides to go for a walk, looks for a clearing but doesn't find it, stops for lunch. 
c. Georgina eats his breakfast, goes for a walk in the misty weather, and then backs to the hotel at night.

d. Georgina decides to go for a walk, gets lost in the forest, cooks the lunch for herself, and finally finds her way and backs to the hotel.

\section{Section 2}

\section{You have 5 minutes to quickly read the text and answer the questions that follow it.}

\section{Speed Reading Test}

Reading is becoming more and more important in the new knowledge economy and remains the most effective human activity for transforming information into knowledge.

If top readers read at speeds of above 1000 words per minute (wpm) with near $85 \%$ comprehension, they only represent $1 \%$ of readers. Average readers are the majority and only reach around $200 \mathrm{wpm}$ with a typical comprehension of $60 \%$. This seems surprising since most readers, actively reading work documents, newspapers, magazines, books or the contents of a computer display are practicing daily for at least one hour. With such an intense training everyone should be close to top performances.

Compare the results of the average reader to other areas. We may imagine a sprinter practicing every day for several years on the running track and then just calmly walking for a race. We can also picture a racing driver never exceeding $30 \mathrm{mph}$ or a pianist playing every day of the week for 20 years and only able to play music like a beginner. Unfortunately, since the age of 12 , most readers do not substantially improve their efficiency and never reach their full capacity.

Every computer-user who is also a slow typist is aware of the benefits he could obtain with a typing course, but nearly no one suspects the much higher profits he could reach by improving his reading comprehension and speed. The rapid improvement of voice recognition may gradually make typing virtuosity obsolete since a good typist performs well under the speed of speech. On the other hand, human or computer speaking, with an average speed of $150 \mathrm{wpm}$, will always remain many times slower than a good reader, without any consideration of the skimming and skipping possibilities.

There are three possible ways to improve reading. The fastest is probably a speed reading seminar based upon good materials and animated by a dynamic instructor. It is quite usual for a slow reader to double and even triple his reading efficiency during a two-day class offering a positive atmosphere, carefully selected texts and comprehension tests. However, as this rapid and encouraging improvement is not sufficiently anchored, it often fades with time.

A book about speed reading is the second possibility. Such a book usually provides speed and comprehension tests as well as techniques to improve reading. It often includes more general information about concentration, interest stimulation, skimming techniques and ways to approach a text. Some methods may include audio or videocassettes. A book-based method 


\section{Macrothink \\ International Journal of English Language Education \\ ISSN 2325-0887 \\ 2013, Vol. 1, No. 3}

requires a good deal of time as well as a strong commitment from the reader.

Finally, a speed reading computer program is probably the most efficient way to achieve top reading levels. Computers offer unique exercises to boost reading efficiency through interactivity, text animation and pacing. Higher reading skills obtained with a computer screen are totally transferable to reading from paper. Unfortunately the inverse way does not work so well. Speed reading software delivers enjoyable and fast paced training, thus giving the consistent practice necessary to break lifelong slow reading habits. This is the task that seminars and speed reading books usually leave up to the reader.

8. Readers reading above $1000 \mathrm{wpm}$ ?
a. are average readers
b. are the majority of readers
c. are the $1 \%$ minority
d. are the $60 \%$ of readers

9. The average reading speed is around?
a. $120 \mathrm{wpm}$
b. $150 \mathrm{wpm}$
c. $200 \mathrm{wpm}$
d. $300 \mathrm{wpm}$

10. The average reader comprehension is around?
a. $50 \%$
b. $60 \%$
c. $85 \%$
d. $90 \%$

11. The average driving speed of a race driver is around?
a. $60 \mathrm{mph}$
b. $20 \mathrm{mph}$
c. $12 \mathrm{mph}$
d. $30 \mathrm{mph}$

12. Most computer users want to?
a. improve typing
b. improve reading 
c. buy a larger screen

d. improve word recognition

13. A speed reading seminar or book lacks?
a. rapid results
b. consistent practice
c. deep enough explanations
d. audio or videocassettes

14. What is probably the best way to reach top level reading efficiency?
a. a speed reading book
b. a speed reading seminar
c. a speed reading software
d. a speed reading quiz

\section{Section 3}

\section{You have 10 minutes to read the text and answer the questions that follow it.}

The origins of nest-building remain obscure, but current observations of nestbuilding activities provide evidence of their evolution. Clues to this evolutionary process can be found in the activities of play and in the behavior and movements of birds during mating, such as incessant pulling at strips of vegetation or scraping of the soil. During the early days of the reproductive cycle, the birds seem only to play with the building materials. In preparation for mating, they engage in activities that resemble nest-building, and continue these activities throughout and even after the mating cycle. Effective attempts at construction can occur only after mating.

Although nest-building is an instinctive ability, there is considerable adaptability in both site selection and use of materials, especially with those species which build quite elaborate constructions. Furthermore, some element of learning is often evident since younger birds do not build as well as their practiced elders. Young ravens, for example, first attempt to build with sticks of quite unsuitable size, while a jackdaw's first nest includes virtually any movable object. The novelist John Steinbeck recorded the contents of a young osprey nest built in his garden, which included three shirts, a bath towel, and one arrow.

Birds also display remarkable behavior in collecting building materials. Crows have been seen to tear off stout green twigs. And sparrowhawks will dive purposefully onto a branch until it snaps and then hang upside down to break it off. Golden eagles, over generations of work, construct enormous nests. One of these, examined after it had been dislodged by high winds, weighed almost two tons and included foundation branches almost two meters long. 


\section{Macrothink}

The carrying capacity of the eagles, however, is only relative to their size and most birds are able to carry an extra load of just over twenty- percent of their body weight.

15. The word "obscure" in line 1 is closest in meaning to
a. interesting
b. unclear
c. imperfect
d. complex

16. According to the passage which of the following activities is characteristic of the early part of the reproductive cycle of birds?
a. selecting a mate
b. collecting nest-building materials
c. playing with nest-building materials
d. building a nest

17. The word "display" in line 18 is closest in meaning to
a. communicate
b. imitate
c. initiate
d. exhibit

18. The novelist John Steinbeck is mentioned in line 15 because he
a. conducted a scientific study on the behavior of ospreys
b. was the first to describe where ospreys built their nest
c. described the materials ospreys can use to build their nests
d. compared the size of ospreys nest with the nests of other species

19. According to the passage, what do sparrowhawks do when gathering materials to build their nests?
a. hang upside down
b. select only green twigs
c. use objects blowing in the wind
d. collect more branches than necessary

20. The word "load" in line 24 is closest in meaning to 

a. weight
b. number
c. section
d. level

21. The author mentions twenty percent in line 24 to indicate that
a. eagles are twenty percent bigger than most birds
b. twenty percent of all nests include foundation branches
c. the nests of eagles are twenty percent larger than those of other birds
d. birds can carry twenty percent of their own weight

\section{Section 4}

\section{You have 10 minutes to read the text and answer the questions that follow it.}

Of all modern instruments, the violin is apparently one of the simplest. It consists in essence of a hollow, varnished wooden sound box, or resonator, and a long neck, covered with a fingerboard, along which four strings are stretched at high tension. The beauty of design, shape, and decoration is no accident: the proportions of the instrument are determined almost entirely by acoustical considerations. Its simplicity of appearance is deceptive. About 70 parts are involved in the construction of a violin. Its tone and its outstanding range of expressiveness make it an ideal solo instrument. No less important, however, is its role as an orchestral and chamber instrument. In combination with the larger and deeper-sounding members of the same family, the violins form the nucleus of the modern symphony orchestra.

The violin has been in existence since about 1550. Its importance as an instrument in its own right dates from the early 1600's, when it first became standard in Italian opera orchestras. Its stature as an orchestral instrument was raised further when in 1626 Louis XIII of France established at his court the orchestra known as les vingt-quatre violins du Roy (The King's 24 Violins), which was to become widely famous later in the century.

In its early history, the violins had a dull and rather quiet tone resulting from the fact that the strings were thick and were attached to the body of the instrument very loosely. During the eighteenth and nineteenth century, exciting technical chances were inspired by such composer-violinists as Vivaldi and Tartini. Their instrumental compositions demanded a fuller, clearer, and more brilliant tone that was produced by using thinner strings and a far higher string tension. Small changes had to be made to the violin's internal structure and to the fingerboard so that they could withstand the extra strain. Accordingly, .a higher standard of performance was achieved, in terms of both facility 


\section{Macrothink \\ International Journal of English Language Education \\ ISSN 2325-0887 \\ 2013, Vol. 1, No. 3}

and interpretation. Left-hand technique was considerably elaborated, and new fingering patterns on the fingerboard were developed for very high notes.

22. The word "standard" in line 13 is closest in meaning to
a. practical
b. customary
c. possible
d. unusual

23. "The King's 24 Violins" is mentioned in line 16 to illustrate
a.how the violin became a renowned instrument
b.the competition in the 1600's between French and Italian orchestras
c.the superiority of French violins
d.why the violin was considered the only instrument suitable to be played by royalty

24. What is the main idea presented in paragraph 3 ?

a. The technique of playing the violin has remained essentially the same since the 1600 's.

b. The violin had reached the height of its popularity by the middle of the eighteenth century.

c. The violin is probably the best known and most widely distributed musical instrument in the world.

d. The violin has been modified to fit its evolving musical functions.

25. According to the passage, early violins were different from modern violins in that early violins
a. were heavier
b. broke down more easily
c. produced softer tones
d. were easier to play

26. According to the passage, which of the following contributes to a dull sound being produced by a violin?
a. a small body
b. high string tension
c. thick strings 


\section{Macrothink

d. a long fingerboard

27. Which of the following terms is defined in the passage?
a. resonator (line 2)
b. solo (line 7)
c. left-hand technique (line 26)
d. fingering patterns (line 27)

28. All of the following are mentioned in the passage as contributing to the ability to play modern violin music EXCEPT
a. more complicated techniques for the left hand
b. minor alternations to the structure of the instrument
c. different ways to use the fingers to play very high notes
d. use of rare wood for the fingerboard and neck

\section{Copyright Disclaimer}

Copyright reserved by the author(s).

This article is an open-access article distributed under the terms and conditions of the Creative Commons Attribution license (http://creativecommons.org/licenses/by/3.0/). 